Short Communication

\title{
Experimental Study on Ultrasonic Assisted Electrochemical Micro-Machining of Micro-Dimple Array Structure
}

\author{
Ge Yongcheng, Chen wangwang, Zhu Yongwei* \\ College of Mechanical Engineering, Yangzhou University, Yangzhou, China \\ E-mail: ywzhu@yzu.edu.cn
}

doi: $10.20964 / 2021.01 .36$

Received: 28 June 2020 / Accepted: 16 November 2020 / Published: 30 November 2020

\begin{abstract}
Micro-dimple array structure is a widely accepted approach for friction reduction between mechanical components. At present, there are many methods to form micro-dimple arrays on metal surface, but how to form high-quality and low-cost micro-dimple arrays is still a challenge. Ultrasonic assisted electrochemical micromachining (UAEMM) is considered to be a promising machining technology due to its advantages of high machining efficiency, high machining accuracy and no limitation of mechanical properties of work-piece materials. In this paper, the UAEMM technology is used to process the microdimple array structure on the metal surface. The experimental results show that the voltage is helpful to improve the machining depth, but too much voltage will also reduce the machining accuracy, and the optimal choice of voltage parameter is $2-3 \mathrm{~V}$ voltage. Compared with DC power, pulse power used in UAEMM process can achieve better machining performance. The machining accuracy and surface quality can be further improved by modulating the synchronous relationship between ultrasonic and pulse. Finally, a better micro pit array structure was prepared according to the optimized process parameters, and its friction performance was tested. The results show that under the same conditions, the surface wear of micro-dimple array surface is less than one third of that of the plane surface.
\end{abstract}

Keywords: microdimples; ultrasonic assisted electrochemical micro-machining; friction properties; micro-structures manufacturing

\section{FULL TEXT}

(C) 2021 The Authors. Published by ESG (www.electrochemsci.org). This article is an open access article distributed under the terms and conditions of the Creative Commons Attribution license (http://creativecommons.org/licenses/by/4.0/). 